\title{
An introduction to perfect and imperfect competition via bilateral oligopoly
}

\author{
Alex Dickson ${ }^{1} \cdot$ Simone Tonin ${ }^{2}$ \\ Received: 31 October 2019/Accepted: 23 December 202020 January 2021 \\ (C) The Author(s) 2021, corrected publication 2022
}

\begin{abstract}
This paper explores the study of bilateral oligopoly, in which both sellers and buyers have substantial influence on the market. We lead readers coherently through the key results that emerge from the literature on bilateral oligopoly by means of worked examples based on the same underlying two commodity exchange economy, along with broader consideration of the relevant literature. This allows us to concisely compare the different equilibrium outcomes when agents act simultaneously vs sequentially, and when some/all agents are assumed to behave competitively, giving the reader much-needed straightforward access to the results of this challenging literature.
\end{abstract}

Keywords Exchange economy $\cdot$ Bilateral oligopoly $\cdot$ Cournot-walras $\cdot$ Cournot-nash

JEL Classification C72 $\cdot$ D43 $\cdot$ D51

\section{Introduction}

"It seems impossible to go on with analysing markets under the assumption of perfect competition. Direct observation of economic activity reveals that markets are the fields of "giants", operating simultaneously with a fringe of small competitors. Even partial analysis has taken this picture of the market when proposing oligopoly solutions to describe the outcomes of imperfectly competitive markets. Behind the demand function there is a myriad of "small" price-taking agents, while the supply side is occupied by few agents appearing as giants, contrasting with the dwarfs on the demand side."

Gabszewicz (2013)

Extended author information available on the last page of the article 
The study of market power in imperfectly competitive markets has commanded much attention from economists. The workhorse model of industrial organization economists - that of Cournot competition - takes a partial equilibrium perspective and makes the assumption that only firms have market power. Bilateral oligopoly is a natural generalization of Cournot competition to consider markets in which both sellers and buyers can have market power and so behave strategically in manipulating prices to be more favourable to them. The purpose of this exposition is to introduce the reader to the study of bilateral oligopoly by leading them through non-trivial examples ${ }^{1}$ that illustrate some of the main ideas to emerge from the literature. Furthermore, the examples provide a unified framework to compare different kinds of oligopoly: symmetric oligopoly, where all agents are permitted to act strategically; asymmetric oligopoly, where only some agents act strategically with the rest assumed to behave as price takers; simultaneous oligopoly, where sellers and buyers make their choices without knowledge of others' decisions; and sequential oligopoly, where some agents move first.

Bilateral oligopoly was first introduced by Gabszewicz and Michel (1997). The model is that of an economy in which there are two commodities and agents have "corner endowments", i.e., they are endowed with only one of these two commodities. In a noncooperative game, agents can then choose the amount of their initial endowment to put up in exchange for the other commodity. It is often convenient to think of the first of the two commodities as a consumption good and the second as commodity money (which can be viewed as a numeraire), in which case the agents endowed with the consumption good are called sellers, and those endowed with the commodity money are buyers. Despite the simplicity of the model, this structure is rich enough to study many interesting phenomena that may arise in imperfectly competitive economies. A fruitful line of research focuses on testing the robustness of the partial equilibrium analysis of Cournot oligopolies to general equilibrium models without production where all agents, sellers and buyers, have market power. For instance, Bloch and Ghosal (1997) and Bloch and Ferrer (2001a) study agents' incentives to create submarkets as the Cournot game suggests that firms could gain market power by forming smaller submarkets. Dickson and Hartley (2008) and Amir and Bloch (2009) focus on the existence of Nash equilibrium and the comparative static properties of the equilibrium. Dickson (2013a) pays particular attention to the effect of entry of additional sellers in bilateral oligopoly, comparing the results to the conventional wisdom from the Cournot model, and Dickson and Hartley (2013a) consider whether bilateral oligopoly and Cournot competition are equivalent when there are many buyers.

The bilateral oligopoly model belongs to the line of research on strategic market games initiated by the seminal papers of Shubik (1973), Shapley (1976), and Shapley and Shubik (1977). There are many types of strategic market games (see Giraud (2003) and Levando (2012) for a survey). Here we mention only the "trading post model" and the "window model" which can be seen as different institutional mechanisms through which prices are determined. In the first model, trade is

\footnotetext{
${ }^{1}$ Dickson (2013b) shows that examples with Cobb-Douglas utility functions, very common in the literature, have very peculiar features which do not hold in general.
} 
decentralised through a system of trading posts where commodities are exchanged. Dubey and Shubik (1978) studied the trading post model where only commodity money is used to buy other commodities while Amir et al. (1990) considered the case in which any commodity can be used to buy other commodities. ${ }^{2}$ Differently, Sahi and Yao (1989) studied the window model where trade is centralised by a clearing house in which there is a "window" for each commodity. This model was first proposed informally by Lloyd S. Shapley, and we call it the "Shapley window model". It is important to stress that when there are only two commodities, as in bilateral oligopoly, all three models coincide.

We start our analysis by recasting the classical Cournot game as an exchange game where firms are replaced by sellers characterised by initial endowments and utility functions, and buyers are represented by a demand function. Next, we consider the Cournot-Walras equilibrium concept in exchange economies, introduced by Codognato and Gabszewicz (1991) and Gabszewicz and Michel (1997). This model describes, in a general equilibrium framework, the same kind of imperfect competition as the Cournot game in which the buyers are assumed to be price takers from whence a demand function can be derived. The exchange versions of these cornerstone models to study imperfect competition allow us to compare them with the bilateral oligopoly model in a clear way. In fact all examples in the paper are based on the same exchange economy where sellers have quasi-linear utility functions and buyers have quasi-linear quadratic utility functions that generate a linear demand which does not exhibit wealth effects (so long as wealth is large enough). By comparing the different approaches we find that there are two main differences between the Cournot-Walras approach and the bilateral oligopoly model.

First, bilateral oligopoly describes a symmetric oligopoly since all agents are allowed to act strategically in manipulating prices by changing their actions, whereas the Cournot-Walras approach describes an asymmetric oligopoly where only the sellers are allowed to act strategically while the buyers are assumed to treat prices as given and beyond their control.

Second, the Cournot-Walras approach has an intrinsic two-stage nature which cannot be reconciled with the Cournot-Nash equilibrium of simultaneous-move bilateral oligopoly where all agents act simultaneously. In order to capture the twostage structure considered in Cournot-Walras, we define a sequential bilateral oligopoly, where sellers move in the first stage and buyers move in the second stage, and we adopt subgame-perfect Nash equilibrium as the equilibrium concept. As in bilateral oligopoly, all agents are treated symmetrically in this model, in the sense that no agents are assumed to be price takers.

The comparison between the Cournot-Walras approach and the bilateral oligopoly model raises the question of whether models that impose the behavioural assumption of price taking on some agents can be reconciled with fully strategic models. This is the so-called problem of the "foundations of oligopoly" which seeks to understand under which conditions price taking

\footnotetext{
${ }^{2}$ A strategic market game with trading post and fiat money was considered by Postlewaite and Schmeidler (1978) and Peck et al. (1992).
} 
behaviour emerges endogenously, and therefore whether the assumption of price taking is appropriate. We deal with this question by replicating the economy to increase the number of buyers while leaving the number of sellers fixed (which we do by following the partial replica approach proposed by Dickson and Hartley (2013a) which replicates the set of buyers while proportionally reducing their weight). As we do so, buyers lose their ability to influence prices and so behave more and more like price takers. We provide an example showing that, in the many-buyer limit, the equilibrium in a sequential version of bilateral oligopoly in which the sellers move first and the buyers move second coincides with the Cournot-Walras equilibrium (that has the same sequential nature but assumes price taking) so sequential bilateral oligopoly provides a foundation for the Cournot-Walras approach. In contrast, the equilibrium in the simultaneous version of bilateral oligopoly remains distinct from the Cournot-Walras equilibrium even in the many-buyer limit. As such, to provide a foundation for the Cournot(Walras) equilibrium concept a large number of buyers is necessary but not sufficient: buyers must also move after sellers have irreversibly committed to their decisions.

In the last part of our paper, we study the relationship between the Walras (competitive) equilibrium and the other equilibrium concepts examined. To this end, we show an example where, when all agents in the economy are replicated as in Debreu and Scarf (1963), sellers' and buyers' commodity bundles at the limit of the Cournot-Nash equilibrium in simultaneous bilateral oligopoly correspond to the commodity bundles at the Walras equilibrium. This is not surprising because, as in the partial replica, when agents are replicated they lose market power and in the limit behave competitively. Since all agents are replicated, in the limit everyone behaves competitively and then the outcome must be Walrasian. Therefore, the bilateral oligopoly model can be used to study the foundations of perfect competition as price taking behaviours can be obtained endogenously in equilibrium when the number of all agents increases without bound. ${ }^{3}$

We conclude our analysis by making some welfare comparisons of the different types of competition analysed. By the first welfare theorem, the Walras equilibrium is Pareto efficient while the allocations obtained with the other equilibrium concepts are Pareto inefficient. This can easily be seen because there exists an allocation that Pareto dominates the one obtained at any equilibrium different from the Walras equilibrium. In other words, when markets are imperfectly competitive the equilibrium outcome is Pareto inefficient.

The rest of the paper has the following structure. In Sect. 2 we introduce the Cournot exchange game. In Sect. 3 we describe the Cournot-Walras approach. In Sect. 4 after having defined the simultaneous bilateral oligopoly model and the Cournot-Nash equilibrium, we give an example with a finite number of agents and an example where we partially replicate the exchange economy concluding there may be differences between a simultaneous bilateral oligopoly and the Cournot-Walras approach even when the number of buyers is large. In Sect. 5 we introduce the sequential bilateral oligopoly model, we partially replicate the exchange economy,

\footnotetext{
$\overline{3}$ See Gale (2000) for a discussion on why the study of the foundations of perfect competition is important.
} 
and we compare the limit of the subgame-perfect Nash equilibrium with the CournotWalras equilibrium. In Sect. 6 we compare our previous results with the Walras equilibrium and we make some welfare considerations. In Sect. 7 we draw some conclusions and we outline some open problems.

\section{Cournot game (partial equilibrium analysis)}

"Let us now imagine two proprietors and two springs of which the qualities are identical, and which, on account of their similar positions, supply the same market in competition."

\section{A. A. Cournot (1838)}

In this section, by taking a slightly different approach from the one proposed by Cournot (1838), we consider the two proprietors as sellers of water and not as producers. This means that they are characterised by an endowment of the good and utility functions instead of cost functions. ${ }^{4}$ Note, however, that with a quasi-linear utility specification as we use in our examples, the two approaches are very similar as the disutility from not consuming the good when it is supplied to the market can be interpreted as a cost of supply. The consumption good (water in Cournot's example) is denoted by $x$ and it is exchanged for money which is denoted by $y .^{5}$ A commodity bundle $(x, y)$ is a point in $\mathbb{R}_{+}^{2}$ which is the set of all feasible commodity bundles. As in Cournot (1838), we assume that buyers are represented by the demand for the consumption good which is a downward sloping function of the price, i.e., $D=f\left(p_{x}\right)$. Each seller is characterized by a utility function, $u_{i}: \mathbb{R}_{+}^{2} \rightarrow \mathbb{R}$, which represents their preferences, and by an initial endowment, $\left(x_{i}^{0}, y_{i}^{0}\right) \in \mathbb{R}_{+}^{2}$, such that $x_{i}^{0}>0$ and $y_{i}^{0}=0$, i.e., sellers hold only the consumption good. Sellers face the demand and we assume that they choose a supply of the consumption good in order to obtain a commodity bundle which maximises their utility. We suppose that there are $m$ sellers.

We now introduce the Cournot exchange game $\Gamma$. The strategy set of seller $i$ is

$$
\mathcal{Q}_{i}=\left\{q_{i} \in \mathbb{R}: 0 \leq q_{i} \leq x_{i}^{0}\right\},
$$

with $q_{i}$ the offer of the consumption good that seller $i$ puts up in exchange for money. Let $\mathcal{Q}=\prod_{i=1}^{m} \mathcal{Q}_{i} \quad$ and $\quad \mathcal{Q}_{-h}=\prod_{i \neq h} \mathcal{Q}_{i} . \quad$ Let $\quad \mathbf{q}=\left(q_{1}, \ldots, q_{m}\right)$ and $\quad \mathbf{q}_{-i}=$ $\left(q_{1}, \ldots, q_{i-1}, q_{i+1}, \ldots, q_{m}\right)$ be elements of $\mathcal{Q}$ and $\mathcal{Q}_{-i}$ respectively. We denote by $Q=\sum_{i=1}^{m} q_{i}$ the total amount of the consumption good offered for sale by sellers.

\footnotetext{
${ }^{4}$ In contrast to the classical partial equilibrium analysis, we consider sellers as being endowed with the good and deciding how much of that good to send to market in exchange for commodity money to maximize their utility of consumption, rather than maximizing profit after defining a cost function. We do so because in the rest of the paper we deal with two commodity exchange economies, a simple general equilibrium framework in which the availability of the two goods is fixed and sellers are characterized by their holdings of the good (rather than their production technologies) and we consider agents whose utility depends positively on both commodities.

${ }^{5}$ Commodity $y$ should be called commodity money because it enters in the utility function. However, for simplicity, we simply refer to it as money.
} 
Cournot's model implicitly assumes there is an auctioneer who adjusts the price so that the market clears, that is, total supply equals the amount demanded. As such, for each $\mathbf{q} \in \mathcal{Q}$, the price of the consumption good is $p_{x}(\mathbf{q})=f^{-1}(Q)$ which implies $D=Q$ and $p_{y}$ is normalized to 1 . For each $\mathbf{q} \in \mathcal{Q}$, the commodity bundle $\left(x_{i}(\mathbf{q}), y_{i}(\mathbf{q})\right)$ of a seller $i$ is given by

$$
\begin{aligned}
& x_{i}(\mathbf{q})=x_{i}^{0}-q_{i}, \\
& y_{i}(\mathbf{q})=p_{x}(\mathbf{q}) \cdot q_{i},
\end{aligned}
$$

for $i=1, \ldots, m$. The payoff function of a seller $i$ is

$$
\pi_{i}(\mathbf{q})=u_{i}\left(x_{i}(\mathbf{q}), y_{i}(\mathbf{q})\right)
$$

for $i=1, \ldots, m$. A Cournot exchange game is then a set $\Gamma=\left\{\left(\mathcal{Q}_{i}, \pi_{i}(\cdot)\right)_{i=1}^{m}\right\}$. We now introduce the definition of a Cournot equilibrium.

Definition 1 The strategy profile $\hat{\mathbf{q}}$ is a Cournot equilibrium for the game $\Gamma$ if for each seller $i=1, \ldots, m$ we have $\pi_{i}\left(\hat{q}_{i}, \hat{\mathbf{q}}_{-i}\right) \geq \pi_{i}\left(q_{i}, \hat{\mathbf{q}}_{-i}\right)$, for each $q_{i} \in \mathcal{Q}_{i}$.

We now consider an example to illustrate the Cournot equilibrium concept.

Example 1 Consider a market with two sellers such that $u_{i}(x, y)=\ln (1+x)+y$ and $\left(x_{i}^{0}, y_{i}^{0}\right)=(3,0)$, for $i=1,2$. Buyers are represented by the demand function $D=6-2 p_{x}$. Since we assume that the market for the consumption good clears, $D=q_{1}+q_{2}$, we obtain $p_{x}(\mathbf{q})=3-\frac{1}{2}\left(q_{1}+q_{2}\right)$. To find the Cournot equilibrium we need to find the strategies $\hat{q}_{1}$ and $\hat{q}_{2}$ which maximise the sellers' payoffs. Consider, without loss of generality, the maximisation problem for seller 1

$$
\begin{array}{cc}
\max _{q_{1}} & \ln \left(1+\left(3-q_{1}\right)\right)+\left(3-\frac{1}{2}\left(q_{1}+q_{2}\right)\right) q_{1}, \\
\text { subject to } & 0 \leq q_{1} \leq 3 .
\end{array}
$$

This payoff function is strictly concave in $q_{1}$, and an easy way to find the maximum is to solve the problem as an unconstrained maximisation problem then check the constraints are satisfied. The first-order condition is

$$
\frac{\partial \pi_{1}}{\partial q_{1}}=-\frac{1}{4-q_{1}}+3-q_{1}-\frac{q_{2}}{2}=0 .
$$

Since sellers are identical, we consider the symmetric Cournot equilibrium where $\hat{q}_{1}=\hat{q}_{2}$, in which

$$
\left(\hat{q}_{1}, \hat{q}_{2}\right)=\left(\frac{9-\sqrt{15}}{3}, \frac{9-\sqrt{15}}{3}\right)
$$

(which, of course, satisfies the constraints). At the Cournot equilibrium the price is $p_{x}(\hat{\mathbf{q}})=\frac{\sqrt{15}}{3}$, demand for the consumption good is $D=\frac{18-2 \sqrt{15}}{3}$ and the sellers' commodity bundles are 


$$
\left(x_{i}(\hat{\mathbf{q}}), y_{i}(\hat{\mathbf{q}})\right)=\left(\frac{\sqrt{15}}{3}, \frac{3 \sqrt{15}-5}{3}\right) \text {, for } i=1,2 .
$$

While we consider a slight variation on the original Cournot model as we treat firms as sellers with utility functions, the underlying principles are exactly the same. Shubik (1973) raised the following critique to this type of oligopoly model:

"The Cournot duopoly model is an open market model involving money. After trade has taken place neither the amount of goods nor the amount of money in the system is conserved. Goods flow out into the market and money flows in from the market."

Shubik's paper advocates a closed market model, where commodities flow within the system and after trade the total amount of each commodity does not change. In our example due to our treatment of the sellers the amount of the consumption good is preserved, but it is immediate to see that the final amount of money is coming from outside the model. This is a typical feature of partial equilibrium models where each market is considered in isolation from the rest of the economy. Therefore, M. Shubik is suggesting to study oligopoly within a general equilibrium model. Furthermore, another critical feature of the Cournot exchange game is that agents are modelled in different ways: sellers are represented by utility functions and initial endowments while buyers are represented by a demand function. ${ }^{6}$

In the next section we address these two issues by introducing a two-commodity exchange economy with corner initial endowments and by using the Cournot-Walras equilibrium as solution concept.

\section{Cournot-Walras approach}

We start by defining the buyers who have been represented by a demand function in the previous model. A buyer is characterised by a utility function $u_{i}: \mathbb{R}_{+}^{2} \rightarrow \mathbb{R}$ which represents their preferences and by an initial endowment, $\left(x_{i}^{0}, y_{i}^{0}\right) \in \mathbb{R}_{+}^{2}$, such that $x_{i}^{0}=0$ and $y_{i}^{0}>0$, i.e., buyers hold only money. We suppose that there are $n$ buyers in the exchange economy indexed $i=m+1, \ldots, m+n$. The difference between sellers and buyers in this model lies in the initial endowments: sellers hold only the consumption good while buyers hold only money (the availability of which is therefore fixed at their total endowment). We can now formally define an exchange economy $\mathcal{E}=\left\{\left(u_{i}(\cdot),\left(x_{i}^{0}, y_{i}^{0}\right)\right)_{i=1}^{m+n}\right\}$ which is the set containing all the pairs $\left(u_{i}(\cdot),\left(x_{i}^{0}, y_{i}^{0}\right)\right)$ describing sellers and buyers. In two-commodity exchange economies the price vector is simply $\mathbf{p}=\left(p_{x}, p_{y}\right)$.

We now describe the agents' behaviours in the Cournot-Walras approach. In the Cournot game sellers were permitted to act strategically while buyers' behaviour was not modelled but represented by a demand function. The Cournot-Walras approach

\footnotetext{
${ }^{6}$ Pantaleoni (1908) pointed out that Leon Walras was dissatisfied by the "approximative way" in which the demand curve was introduced by Cournot in his analysis.
} 
derives the Walrasian (competitive) demands of the buyers from their characteristics making the explicit assumption that they are price takers. The Walrasian demands of a buyer $i$ are the functions $x_{i}(\mathbf{p})$ and $y_{i}(\mathbf{p})$ that associate to each positive price vector an amount of commodity $x$ and $y$ that maximises the utility function $u_{i}(\cdot)$ in $i$ 's budget set $\left\{(x, y) \in \mathbb{R}_{+}^{2}: p_{x} x+p_{y} y \leq p_{y} y_{i}^{0}\right\} .^{7}$ In other words, for any positive price vector $\mathbf{p}$, the amounts $x_{i}(\mathbf{p})$ and $y_{i}(\mathbf{p})$ solve the following maximisation problem ${ }^{8}$

$$
\begin{array}{cc}
\max _{(x, y) \in \mathbb{R}_{+}^{2}} & u_{i}(x, y), \\
\text { subject to } & p_{x} x+p_{y} y \leq p_{y} y_{i}^{0},
\end{array}
$$

for any buyer $i$. We assume again that the market of each commodity clears. Therefore, for each $\mathbf{q} \in \mathcal{Q}$, the price vector $\mathbf{p}$ at a Cournot-Walras equilibrium must solve

$$
\sum_{i=m+1}^{m+n} x_{i}(\mathbf{p})=\sum_{i=1}^{m} q_{i},
$$

i.e., buyers' total demand of the consumption good must be equal to sellers' total supply of the consumption good. We denote by $\mathbf{p}(\mathbf{q})$ the price vector $\left(p_{x}(\mathbf{q}), 1\right)$ that solves equation (5). ${ }^{9}$ If equation (5) holds then the market for money also clears. By having described the price formation rule, which is purely Walrasian, we can now define the rules to calculate the commodity bundle of each agent. The buyers' commodity bundles are given by the Walrasian demands calculated at the price vector $\mathbf{p}(\mathbf{q})$. Since sellers' strategies are the same as in the Cournot exchange game, their commodity bundles are given according to the equations in (2) at the price vector $\mathbf{p}(\mathbf{q})$. Consequently sellers' payoff functions are defined as in (3). We finally introduce the notion of an allocation $\left(x_{i}, y_{i}\right)_{i=1}^{n+m}$ which is a specification of a commodity bundle for each seller and buyer.

We now have all the elements to define the Cournot-Walras equilibrium for the exchange economy $\mathcal{E}$.

Definition 2 A Cournot-Walras equilibrium for the exchange economy $\mathcal{E}$ is a vector $\tilde{\mathbf{q}}$ and an allocation $\left(\tilde{x}_{i}, \tilde{y}_{i}\right)_{i=1}^{n+m}$ such that

- for each seller $i=1, \ldots, m$ we have $u_{i}\left(x_{i}\left(\tilde{q}_{i}, \tilde{\mathbf{q}}_{-i}\right)\right.$, $\left.y_{i}\left(\tilde{q}_{i}, \tilde{\mathbf{q}}_{-i}\right)\right) \geq u_{i}\left(x_{i}\left(q_{i}, \tilde{\mathbf{q}}_{-i}\right), y_{i}\left(q_{i}, \tilde{\mathbf{q}}_{-i}\right)\right)$, for each $q_{i} \in \mathcal{Q}_{i}$;

$-\left(\tilde{x}_{i}, \tilde{y}_{i}\right)=\left(x_{i}(\tilde{\mathbf{q}}), y_{i}(\tilde{\mathbf{q}})\right)$ for the sellers $i=1, \ldots, m$ and $\left(\tilde{x}_{i}, \tilde{y}_{i}\right)=$ $\left(x_{i}(\mathbf{p}(\tilde{\mathbf{q}})), y_{i}(\mathbf{p}(\tilde{\mathbf{q}}))\right)$ for the buyers $i=m+1, \ldots, n$.

\footnotetext{
${ }^{7}$ More generally, Walrasian demands can be correspondences which associate to each price the set of commodity bundles which maximise the utility function in the budget set. For the sake of simplicity, we just consider the case in which Walrasian demands are functions.

${ }^{8}$ Note that this maximisation problem has a solution only for continuous utility functions and positive prices.

${ }^{9}$ To avoid cumbersome notation, but without confusion, we denote the same elements of different models with the same symbol.
} 
We now consider an example to illustrate the Cournot-Walras equilibrium concept.

Example 2 Consider an exchange economy with 2 sellers and 2 buyers such that $u_{i}(x, y)=\ln (1+x)+y$ and $\left(x_{i}^{0}, y_{i}^{0}\right)=(3,0)$, for $i=1,2$ (the sellers), and $u_{i}(x, y)=$ $3 x-\frac{1}{2} x^{2}+y$ and $\left(x_{i}^{0}, y_{i}^{0}\right)=(0,5)$, for $i=3,4$ (the buyers). ${ }^{10}$ To calculate a Cournot-Walras equilibrium, the first step is to find buyers' Walrasian demands. The constrained maximisation problem the buyers face is

$$
\begin{array}{cc}
\max _{(x, y) \in \mathbb{R}_{+}^{2}} & 3 x-\frac{1}{2} x^{2}+y, \\
\text { subject to } & p_{x} x+p_{y} y \leq p_{y} 5 .
\end{array}
$$

By using the Lagrange multiplier method, we can obtain the Walrasian demands

$$
x_{i}(\mathbf{p})=3-\frac{p_{x}}{p_{y}} \text { and } y_{i}(\mathbf{p})=\frac{5 p_{y}^{2}+p_{x}^{2}-3 p_{x} p_{y}}{p_{y}^{2}},
$$

for $i=3,4$. Study of the second-order conditions reveals the solution corresponds to a maximum. ${ }^{11}$ Since we normalise $p_{y}=1$, the price of the consumption good which solves equation (5) is

$$
p_{x}(\mathbf{q})=3-\frac{1}{2}\left(q_{1}+q_{2}\right) .
$$

By construction, this is the same inverse demand function as in Example 1, but derived from buyers' characteristics rather than assumed. Therefore, it is immediate to see that each seller's maximisation problem is equivalent to that in (4) from Example 1, so $\left(\tilde{q}_{1}, \tilde{q}_{2}\right)=\left(\frac{9-\sqrt{15}}{3}, \frac{9-\sqrt{15}}{3}\right)$ and $\mathbf{p}(\tilde{\mathbf{q}})=\left(\frac{\sqrt{15}}{3}, 1\right)$. Finally, the allocation at the Cournot-Walras equilibrium is

$$
\begin{gathered}
\left(x_{i}(\tilde{\mathbf{q}}), y_{i}(\tilde{\mathbf{q}})\right)=\left(\frac{\sqrt{15}}{3}, \frac{3 \sqrt{15}-5}{3}\right), \text { for } i=1,2, \\
\left(x_{i}(p(\tilde{\mathbf{q}})), y_{i}(p(\tilde{\mathbf{q}}))\right)=\left(\frac{9-\sqrt{15}}{3}, \frac{20-3 \sqrt{15}}{3}\right), \text { for } i=3,4 .
\end{gathered}
$$

It is immediate to see that sellers' commodity bundles and the total demand of the consumption good from buyers correspond to the ones at the Cournot equilibrium. Therefore, the Cournot-Walras equilibrium captures, in a general equilibrium framework, the same kind of competition as the Cournot exchange game but where the total quantities of the two commodities in the system are preserved, and buyers'

\footnotetext{
${ }^{10}$ We use quadratic utility functions as the implied demand function from the buyers is then linear. Note that each buyer's utility function reaches a point of saturation at $x=3$; however, as the total endowment of commodity $x$ is 6 and we consider two symmetric buyers we will not be in danger of examining solutions that breach this saturation point.

${ }^{11}$ It is worth noting that, since the utility functions are quasi-linear, there can be corner solutions. However, for the sake of simplicity and since this does not affect our analysis, we just consider interior solutions.
} 
behaviour is explicitly modelled, assuming they are price takers. In other words, the Cournot-Walras approach allows us to study asymmetric oligopoly in a general equilibrium setting, with sellers acting strategically and buyers assumed to treat prices as fixed. Therefore, oligopoly models based on exchange economies can address Shubik (1973)'s critique.

The Cournot-Walras equilibrium concept was introduced by Gabszewicz and Vial (1972) in a production economy and it was recast in exchange economies by Codognato and Gabszewicz (1991) and subsequently by Gabszewicz and Michel (1997). These contributions consider exchange economies characterised by few oligopolists (sellers in our case) and many small agents (buyers in our case). In the Cournotian spirit, the oligopolists are allowed to act strategically as they are few, while small agents are assumed to act competitively as price takers as they are many. However this kind of assumption was criticised by Okuno et al. (1980):

"Traditional general equilibrium treatments of such situations [in which some but not all agents have market power] have been deficient in that they have simply assumed a priori that certain agents behave as price takers while others act non-competitively, with no formal explanation being given as to why a particular agent should behave one way or the other."

Our Example 2 supports this view as it shows that it is possible to use the Cournot-Walras equilibrium in odd cases where buyers are assumed to behave competitively even if there are only two of them. In other words, the Cournot-Walras approach does not endogenously derive agents' behaviours but it assumes a priori that some agents can influence prices while others are price takers. ${ }^{12}$

The issue of asymmetrically imposing behavioural assumptions on some agents is overcome in bilateral oligopoly models in which both sellers and buyers are treated symmetrically in that all agents are allowed to behave strategically—no price-taking assumptions are imposed a priori-and, departing from the Walrasian tradition, the price is constructed from agents strategic decisions.

\section{Simultaneous bilateral oligopoly}

As stressed in the introduction, the bilateral oligopoly model is a strategic market game based on a two-commodity exchange economy with corner initial endowments. ${ }^{13}$ We define the exchange economy $\mathcal{E}=\left\{\left(u_{i}(\cdot),\left(x_{i}^{0}, y_{i}^{0}\right)\right)_{i=1}^{m+n}\right\}$ as in the

\footnotetext{
12 A further shortcoming of the Cournot-Walras approach is that it is extremely challenging to obtain a general existence result because oligopolists influence prices by manipulating the Walras price correspondence which may fail to be continuous unless strict assumptions are imposed on the set of price-taking agents. Nevertheless, some existence results have been obtained in particular frameworks: Bonisseau and Florig (2003) proved the existence of a Cournot-Walras equilibrium in linear exchange economies; Codognato and Julien (2013) proved the existence in mixed exchange economies where agents on the continuum have Cobb-Douglas utility functions; and Shirai (2010) proves the existence of a Cournot-Walras equilibrium in production economies.

${ }^{13}$ Bloch and Ferrer (2001a) and Dickson and Hartley (2013b) also consider the case in which agents are endowed with both commodities, i.e. have "interior" initial endowments, and can choose whether they become sellers or buyers.
} 
previous section. The strategy set of a seller $i$ is defined as in (1). The strategy set of a buyer $i$ is

$$
\mathcal{B}_{i}=\left\{b_{i} \in \mathbb{R}: 0 \leq b_{i} \leq y_{i}^{0}\right\} .
$$

The strategy $b_{i}$ is the bid of money that buyer $i$ makes on the consumption good. Let $\mathcal{B}=\prod_{i=1}^{m+n} \mathcal{B}_{i} \quad$ and $\quad \mathcal{B}_{-h}=\prod_{i \neq h} \mathcal{B}_{i} . \quad$ Let $\quad \mathbf{b}=\left(b_{m+1}, \ldots, b_{m+n}\right) \quad$ and $\quad \mathbf{b}_{-i}=$ $\left(b_{m+1}, \ldots, b_{i-1}, b_{i+1}, \ldots, b_{m+n}\right)$ be elements of $\mathcal{B}$ and $\mathcal{B}_{-i}$ respectively. For each $(\mathbf{q}, \mathbf{b}) \in \mathcal{Q} \times \mathcal{B}$, the price vector $\mathbf{p}(\mathbf{q}, \mathbf{b})=\left(p_{x}(\mathbf{q}, \mathbf{b}), 1\right)$ is determined such that the price of the consumption good is given by the ratio of the total money bids made for the good to the total amount of good made available by the sellers:

$$
p_{x}(\mathbf{q}, \mathbf{b})=\left\{\begin{array}{ll}
\frac{B}{Q} & \text { if } Q \neq 0 \\
0 & \text { if } Q=0
\end{array},\right.
$$

with $B=\sum_{i=m+1}^{m+n} b_{i}$. Having defined the price formation rule, which is non-Walrasian, we can now define the rules to calculate the commodity bundles of each agent. For each $(\mathbf{q}, \mathbf{b}) \in \mathcal{Q} \times \mathcal{B}$, the commodity bundle $\left(x_{i}(\mathbf{q}, \mathbf{b}), y_{i}(\mathbf{q}, \mathbf{b})\right)$ of a seller $i$ is given by

$$
\begin{aligned}
& x_{i}(\mathbf{q}, \mathbf{b})=x_{i}^{0}-q_{i}, \\
& y_{i}(\mathbf{q}, \mathbf{b})=p_{x}(\mathbf{q}, \mathbf{b}) \cdot q_{i},
\end{aligned}
$$

for $i=1, \ldots, m$, and the commodity bundle $\left(x_{i}(\mathbf{q}, \mathbf{b}), y_{i}(\mathbf{q}, \mathbf{b})\right)$ of a buyer $i$ is given by

$$
\begin{aligned}
& x_{i}(\mathbf{q}, \mathbf{b})=\left\{\begin{array}{cc}
\frac{b_{i}}{p_{x}(\mathbf{q}, \mathbf{b})} & \text { if } p_{x}(\mathbf{q}, \mathbf{b}) \neq 0 \\
0 & \text { if } p_{x}(\mathbf{q}, \mathbf{b})=0
\end{array},\right. \\
& y_{i}(\mathbf{q}, \mathbf{b})=y_{i}^{0}-b_{i},
\end{aligned}
$$

for $i=m+1, \ldots, m+n$. As such, each agent's amount of the commodity they are endowed with reduces by the quantity of that commodity they offer to the market, and the amount of the other commodity is given by their proportional share of the aggregate amount of that commodity offered by the other side of the market, so sellers receive a share $q_{i} / Q$ of the aggregate bid $B$, and buyers receive a share $b_{i} / B$ of the aggregate offer $Q$. The payoff function of agent $i$ is $\pi_{i}(\mathbf{q}, \mathbf{b})=u_{i}\left(x_{i}(\mathbf{q}, \mathbf{b}), y_{i}(\mathbf{q}, \mathbf{b})\right)$, for $i=1, \ldots, m+n$. The simultaneous bilateral oligopoly game is then a set $\Gamma^{\prime}=\left\{\left(\mathcal{Q}_{i}, \pi_{i}(\cdot)\right)_{i=1}^{m},\left(\mathcal{B}_{i}, \pi_{i}(\cdot)\right)_{i=m+1}^{m+n}\right\}$.

The definition of a Cournot-Nash equilibrium in bilateral oligopoly is as follows.

Definition 3 The strategy profile $(\hat{\mathbf{q}}, \hat{\mathbf{b}})$ is a Cournot-Nash equilibrium of the game $\Gamma^{\prime}$ if for each seller $i=1, \ldots, m$ we have $\pi_{i}\left(\hat{q}_{i}, \hat{\mathbf{q}}_{-i}, \hat{\mathbf{b}}\right) \geq \pi_{i}\left(q_{i}, \hat{\mathbf{q}}_{-i}, \hat{\mathbf{b}}\right)$, for each $q_{i} \in \mathcal{Q}_{i}$, and for each buyer $i=m+1, \ldots, m+n$ we have $\pi_{i}\left(\hat{\mathbf{q}}, \hat{b}_{i}, \hat{\mathbf{b}}_{-i}\right) \geq \pi_{i}\left(\hat{\mathbf{q}}, b_{i}, \hat{\mathbf{b}}_{-i}\right)$, for each $b_{i} \in \mathcal{B}_{i}$. 
We now consider an example to illustrate the Cournot-Nash equilibrium concept.

Example 3 Consider the exchange economy defined in Example 2. To find the Cournot-Nash equilibrium, we have to solve the payoff maximisation problems for all agents. We first consider sellers and then buyers. Consider the maximisation problem of seller 1:

$$
\begin{array}{cc}
\max _{q_{1}} & \ln \left(1+\left(3-q_{1}\right)\right)+\frac{b_{3}+b_{4}}{q_{1}+q_{2}} q_{1}, \\
\text { subject to } & 0 \leq q_{1} \leq 3 .
\end{array}
$$

This payoff function is strictly concave in $q_{1}$; we solve as an unconstrained problem then check the solution satisfies the constraints. The first-order condition is

$$
\frac{\partial \pi_{1}}{\partial q_{1}}=-\frac{1}{4-q_{1}}+\frac{b_{3}+b_{4}}{q_{1}+q_{2}}\left(1-\frac{q_{1}}{q_{1}+q_{2}}\right)=0 .
$$

Since all sellers are identical and all buyers are identical, we consider a symmetric Cournot-Nash equilibrium where $\hat{q}_{1}=\hat{q}_{2}=\hat{q}$ and $\hat{b}_{3}=\hat{b}_{4}=\hat{b}$. Then the previous equation becomes,

$$
-\frac{1}{4-\hat{q}}+\frac{\hat{b}}{\hat{q}} \frac{1}{2}=0
$$

and we obtain

$$
\hat{q}=\frac{4 \hat{b}}{2+\hat{b}} .
$$

Consider next the maximisation problem of buyer 3:

$$
\begin{gathered}
\max _{b_{3}} \quad 3 b_{3} \frac{q_{1}+q_{2}}{b_{3}+b_{4}}-\frac{1}{2}\left(b_{3} \frac{q_{1}+q_{2}}{b_{3}+b_{4}}\right)^{2}+\left(5-b_{3}\right), \\
\text { subject to } \\
0 \leq b_{3} \leq 5
\end{gathered}
$$

The first order condition of the buyer's unconstrained maximisation problem can be written as

$$
\frac{\partial \pi_{3}}{\partial b_{3}}=\frac{q_{1}+q_{2}}{b_{3}+b_{4}}\left(1-\frac{b_{3}}{b_{3}+b_{4}}\right)\left(3-b_{3} \frac{q_{1}+q_{2}}{b_{3}+b_{4}}\right)-1=0 .
$$

Since we consider the symmetric Cournot-Nash equilibrium, we then obtain

$$
\hat{b}=\hat{q} \frac{1}{2}(3-\hat{q}) .
$$

Study of the second-order conditions reveals the solution corresponds to a maximum. By combining equations (7) and (8), we find that the Cournot-Nash equilibrium for the bilateral oligopoly model is 


$$
\left(\hat{q}_{1}, \hat{q}_{2}, \hat{b}_{3}, \hat{b}_{4}\right)=\left(\frac{7-\sqrt{17}}{2}, \frac{7-\sqrt{17}}{2}, \sqrt{17}-3, \sqrt{17}-3\right) .
$$

At the Cournot-Nash equilibrium the price vector is $\mathbf{p}(\hat{\mathbf{q}}, \hat{\mathbf{b}})=\left(\frac{\sqrt{17}-1}{4}, 1\right)$ and the allocation is

$$
\begin{aligned}
& \left(x_{i}(\hat{\mathbf{q}}, \hat{\mathbf{b}}), y_{i}(\hat{\mathbf{q}}, \hat{\mathbf{b}})\right)=\left(\frac{\sqrt{17}-1}{2}, \sqrt{17}-3\right), \text { for } i=1,2, \\
& \left(x_{i}(\hat{\mathbf{q}}, \hat{\mathbf{b}}), y_{i}(\hat{\mathbf{q}}, \hat{\mathbf{b}})\right)=\left(\frac{7-\sqrt{17}}{2}, 8-\sqrt{17}\right), \text { for } i=3,4 .
\end{aligned}
$$

This example clarifies that the simultaneous bilateral oligopoly model allows us to study oligopoly where all agents are treated symmetrically and no assumptions on their behaviours are made a priori. Indeed, given the structure of the game, all agents act strategically because they can manipulate the price by changing their actions. Therefore, bilateral oligopoly addresses the critique raised by Okuno et al. (1980). The fact that buyers act strategically is one of the reasons why sellers' and buyers' commodity bundles at the Cournot-Nash equilibrium are different from those obtained at the Cournot-Walras equilibrium, even if the exchange economies in Examples 2 and 3 are the same. We stress again that buyers are assumed to behave as price-takers in the Cournot-Walras approach while they are permitted to act strategically in bilateral oligopoly. Furthermore, while the Cournot-Walras model suffers from issues because of the potential discontinuity of the Walras price correspondence, this is not the case in bilateral oligopoly because the price formation rule is non-Walrasian. The existence of a Cournot-Nash equilibrium was studied by Bloch and Ferrer (2001a) and Dickson and Hartley (2008), who also studied uniqueness of equilibrium. Additionally, Bloch and Ferrer (2001b) showed the existence when all agents have a constant elasticity of substitution utility function.

At this point of the analysis a natural question arises: is it possible to employ the bilateral oligopoly model to study asymmetric oligopoly where no a priori assumptions on agents behaviours are made? In other words, is it possible to develop a framework where the differences in agents' behaviours arise endogenously in equilibrium? This is also known as the problem of providing a strategic foundation for oligopoly.

In the literature, two main approaches are used to this end. The first approach consists of using mixed exchange economies where large agents (oligopolists) are represented by atoms and small agents (competitive agents) by an atomless continuum. An atom is an agent whose initial endowment is non-negligible compared to the total endowment of the economy while an agent in the continuum holds only a negligible part of it. The model was proposed by Gabszewicz and Mertens (1971) and Shitovitz (1973) in cooperative game theory. Shitovitz (1973) stated:

"The main point in our treatment is that the small and the large traders are not segregated into different groups a priori; they are treated on exactly the same 
basis. The distinctions we have found between them are an outcome of the analysis; they have not been artificially introduced in the beginning, as is the case in the classical approach."

This approach based on mixed exchange economies was also extended to noncooperative game theory by Okuno et al. (1980), in order to address their critique, and further generalised by Busetto et al. (2011) and Busetto et al. (2018). Busetto et al. (2020) undertake a study of bilateral oligopoly in a mixed exchange economy. In this setting, while all agents have a priori the same strategic position, they found that in equilibrium large agents represented by atoms have market power while small agents on the continuum behave as if they are price-takers.

The second approach is based on considering partial replicas of exchange economies where the number of some agents is increased while proportionally reducing their weights. This method was introduced to bilateral oligopoly by Dickson and Hartley (2013a) and it was subsequently formalized, using the tools of measure theory, by Busetto et al. (2017). The main result of this approach is that agents who are replicated gradually lose their ability to influence prices as their number increases and in the limit they behave as price takers, whereas agents that are not replicated and remain large retain their market power.

In the last part of this section, we consider the second approach and study the limit of partial replicas where we replicate only the set of buyers. We study such a limit because it represents an asymmetric oligopoly where buyers are asymptotically negligible and so should behave as price takers. Consider an exchange economy $\mathcal{E}=\left\{\left(u_{i}(\cdot),\left(x_{i}^{0}, y_{i}^{0}\right)\right)_{i=1}^{m+n}\right\}$ where the first $m$ agents are sellers and all other $n$ agents are buyers. The partially replicated exchange economy $\mathcal{E}^{r}$ consists in an exchange economy having the same sellers as $\mathcal{E}$ and $r$ replicas of each buyer in $\mathcal{E}$. Furthermore, to each buyer is associated a weight $\frac{1}{r}$ which is used to weight buyers when aggregating across them. It is then clear that the aggregate bid must include the weighting factor $\frac{1}{r}$ when partially replicating the economy. For clarity, we denote by $\tilde{B}=\sum_{i=m+1}^{m+n} \sum_{j=1}^{r} \frac{1}{r} b_{i j}$ the weighed sum of bids where $b_{i j}$ is the bid of the $j$ th replica of buyer $i$. This kind of partial replica based on reducing the weight of each buyer as the number of replicas increases allows us to increase the number of buyers, consequently reducing their market power, without the undesirable consequence of the demand for the consumption good exploding while its supply remains fixed (as the number of sellers is fixed) and the price consequently tending to infinity. ${ }^{14}$

\footnotetext{
${ }^{14}$ The weighting is used whenever aggregating across the set of buyers - to construct the aggregate bid as we explained, and also in the aggregation of buyers' endowments and demands when considering market clearing, which therefore takes place at a per-replica level. In the replicated exchange economy $\mathcal{E}^{r}$ an allocation is feasible if it satisfies the following market clearing conditions$$
\sum_{i=1}^{m} x_{i}+\sum_{i=m+1}^{m+n} \sum_{j=1}^{r} \frac{1}{r} x_{i j}=\sum_{i=1}^{m} x_{i}^{0} \text { and } \sum_{i=1}^{m} y_{i}+\sum_{i=m+1}^{m+n} \sum_{j=1}^{r} \frac{1}{r} y_{i j}=\sum_{i=m+1}^{m+n} \sum_{j=1}^{r} \frac{1}{r} y_{i j}^{0} \text {. }
$$

These equations further clarify the role of the weight in avoiding that the demand for the consumption good and the endowment of commodity 2 explode. Furthermore, they also show that there is clear analogy between the weight $\frac{1}{r}$ and the measure of an atom in mixed exchange economies. The interested reader should refer to Busetto et al. (2017) and their definition of partial replica à la Cournot.
} 
Note that given the price formation rule (6) and the definition of $\tilde{B}$, if $r$ increases, then the buyers' ability to influence prices decreases and at the limit, for $r \rightarrow \infty$, totally disappears. Obviously we have that $\mathcal{E}=\mathcal{E}^{1}$. It is important to stress that the limit of a sequence of Cournot-Nash equilibria, which is denoted by $(\overline{\mathbf{q}}, \overline{\mathbf{b}})$, is not a Cournot-Nash equilibrium of the limit economy as the underlying game in the limit is not well-defined. Nevertheless, the limit of the sequence gives us an object that can be compared to the other solution concepts in finite economies.

We now consider an example to illustrate how to partially replicate an exchange economy and how to calculate its limit.

Example 4 Consider the partial replica of the exchange economy defined in Example 2 with $r$ replicas of each buyer. We then have an exchange economy with 2 sellers and $2 r$ buyers, i.e., $u_{i}(x, y)=\ln (1+x)+y$ and $\left(x_{i}^{0}, y_{i}^{0}\right)=(3,0)$, for $i=1,2$ and $u_{i j}(x, y)=3 x-\frac{1}{2} x^{2}+y$ and $\left(x_{i j}^{0}, y_{i j}^{0}\right)=(0,5)$, for $i=3,4$ and $j=1, \ldots, r$. As each buyer has a weight $\frac{1}{r}$, we have that $\tilde{B}=\sum_{j=1}^{r} \frac{1}{r} b_{3 j}+\sum_{j=1}^{r} \frac{1}{r} b_{4 j}$. To simplify the analysis, we consider a symmetric Cournot-Nash equilibrium, where all buyers play the same strategy, and then $\hat{\tilde{B}}=2 \hat{b}$. But then, if we consider the sellers' payoff maximisation problems, it is straightforward to verify that in a symmetric equilibrium sellers' strategies are as in the previous example

$$
\hat{q}=\frac{4 \hat{b}}{2+\hat{b}} .
$$

On the contrary, buyers' maximisation problems are different from the previous example because now there are $2 r$ buyers instead of two. Consider the maximisation problem of buyer $3 h$, i.e., the replica $h$ of buyer 3 :

$$
\max _{b_{3 h}} \quad 3 b_{3 h} \frac{q_{1}+q_{2}}{\sum_{j=1}^{r} \frac{1}{r} b_{3 j}+\sum_{j=1}^{r} \frac{1}{r} b_{4 j}}-\frac{1}{2}\left(b_{3 h} \frac{q_{1}+q_{2}}{\sum_{j=1}^{r} \frac{1}{r} b_{3 j}+\sum_{j=1}^{r} \frac{1}{r} b_{4 j}}\right)^{2}+\left(5-b_{3 h}\right),
$$

subject to

$$
0 \leq b_{3 h} \leq 5 \text {. }
$$

The first order condition of the buyer's unconstrained maximisation problem can be written as

$$
\frac{\partial \pi_{3 h}}{\partial b_{3 h}}=\frac{q_{1}+q_{2}}{\tilde{B}}\left(1-\frac{\frac{1}{r} b_{3 h}}{\tilde{B}}\right)\left(3-b_{3 h} \frac{q_{1}+q_{2}}{\tilde{B}}\right)-1=0 .
$$

Since we consider a symmetric Cournot-Nash equilibrium where $\hat{q}_{1}=\hat{q}_{2}=\hat{q}$ and $\hat{b}_{3 j}=\hat{b}_{4 j}=\hat{b}$ for $j=1, \ldots, r$, from the previous equation we obtain

$$
\hat{b}=\hat{q}\left(1-\frac{1}{2 r}\right)(3-\hat{q}) .
$$

Let $k=1-\frac{1}{2 r}$. By combining equations (9) and (12), we obtain the following Cournot-Nash equilibrium for the bilateral oligopoly model 


$$
\begin{array}{r}
\left(\hat{q}_{1}, \hat{q}_{2}, \hat{b}_{31}, \ldots, \hat{b}_{3 r}, \hat{b}_{41}, \ldots, \hat{b}_{4 r}\right)=\left(\frac{7 k-\sqrt{k^{2}+8 k}}{2 k}, \frac{7 k-\sqrt{k^{2}+8 k}}{2 k},\right. \\
2 \sqrt{k^{2}+8 k}-2 k-2, \ldots, 2 \sqrt{k^{2}+8 k}-2 k-2, \\
\left.2 \sqrt{k^{2}+8 k}-2 k-2, \ldots, 2 \sqrt{k^{2}+8 k}-2 k-2\right) .
\end{array}
$$

The limit of this Cournot-Nash equilibrium as $r \rightarrow \infty$ is $\bar{q}_{i}=2$ for sellers and $\bar{b}_{i j}=2$ for buyers. At the limit the price vector is $\mathbf{p}(\overline{\mathbf{q}}, \overline{\mathbf{b}})=(1,1)$ and the sellers' and buyers' commodity bundles are

$$
\begin{aligned}
& \left(x_{i}(\overline{\mathbf{q}}, \overline{\mathbf{b}}), y_{i}(\overline{\mathbf{q}}, \overline{\mathbf{b}})\right)=(1,2), \text { for a seller } i, \\
& \left(x_{i j}(\overline{\mathbf{q}}, \overline{\mathbf{b}}), y_{i j}(\overline{\mathbf{q}}, \overline{\mathbf{b}})\right)=(2,3), \text { for a buyer } i j .
\end{aligned}
$$

We finally remark that the allocation

$$
\begin{array}{r}
\left(\left(x_{1}, y_{1}\right),\left(x_{2}, y_{2}\right),\left(x_{31}, y_{31}\right), \ldots,\left(x_{3 r}, y_{3 r}\right),\left(x_{41}, y_{41}\right), \ldots,\left(x_{4 r}, y_{4 r}\right)\right)= \\
((1,2),(1,2),(2,3), \ldots,(2,3),(2,3), \ldots,(2,3))
\end{array}
$$

for the partially replicated exchange economy $\mathcal{E}^{r}$ is feasible for any $r$ as the market clearing conditions are satisfied, i.e.,

$$
\begin{array}{r}
x_{1}+x_{2}+\sum_{j=1}^{r}\left(\frac{1}{r} x_{3 j}+\frac{1}{r} x_{4 j}\right)=1+1+r \frac{1}{r}(2+2)=3+3=x_{1}^{0}+x_{2}^{0} \\
y_{1}+y_{2}+\sum_{j=1}^{r}\left(\frac{1}{r} y_{3 j}+\frac{1}{r} y_{4 j}\right)=2+2+r \frac{1}{r}(3+3)=r \frac{1}{r}(5+5)=\sum_{j=1}^{r}\left(\frac{1}{r} y_{3 j}^{0}+\frac{1}{r} y_{4 j}^{0}\right)
\end{array}
$$

It is immediate to see that the commodity bundles at the limit of the Cournot-Nash equilibrium are different from the ones at the Cournot-Walras equilibrium of Example 2. This result is somewhat surprising as at the limit of the Cournot-Nash equilibrium buyers have no influence on the price, as is assumed in the CournotWalras approach, yet the equilibrium allocations differ. This is due to the fact that the Cournot-Walras approach has an intrinsic two-stage structure-sellers decide their supply taking into account their influence on the Walrasian demands of buyerswhereas when considering a Cournot-Nash equilibrium in the bilateral oligopoly model all agents choose their actions simultaneously so sellers must form beliefs about how the buyers will behave. This fact was stressed by Dickson and Hartley (2013a) who considered the conditions under which the two models coincide in the limit, and when they do not. In mixed exchange economies, Codognato (1995) and Busetto et al. (2008) showed that the allocation at a Cournot-Walras equilibrium is different from the one at a Cournot-Nash equilibrium of the Shapley window model. Therefore, we can conclude that the bilateral oligopoly model can be useful to study simultaneous asymmetric oligopoly in a closed market model by partially replicating 
the underlying exchange economy but it does not provide a foundation of the Cournot-Walras approach. In the next section, we address this last issue by studying a sequential bilateral oligopoly model.

\section{Sequential bilateral oligopoly}

In this section we consider a sequential-move bilateral oligopoly model with a twostage structure where the timing of the model is exogenously specified as follows: in the first stage sellers simultaneously choose the quantities of the consumption good to put up in exchange for money; in the second stage, after observing all sellers' offers, the buyers simultaneously choose the quantity of money to bid for the consumption good. At the end of the second stage bids and offers are aggregated and the price is determined according to the usual rule in (6). Groh (1999) first considered a sequential reformulation of bilateral oligopoly in the context of an example, that was extended to general settings in Dickson (2006). ${ }^{15}$

We first consider an exchange economy $\mathcal{E}=\left\{\left(u_{i}(\cdot),\left(x_{i}^{0}, y_{i}^{0}\right)\right)_{i=1}^{m+n}\right\}$ and we then define the sequential bilateral oligopoly. The strategy set of a seller $i$ is defined as in (1). The strategy set of a buyer $i$ is

$$
\mathcal{B}_{i}=\left\{b_{i}(\cdot), \text { a function such that } b_{i}: \mathcal{Q} \rightarrow\left[0, y_{i}^{0}\right]\right\} .
$$

Let $\mathcal{B}=\prod_{i=m+1}^{m+n} \mathcal{B}_{i}$ and $\mathbf{b}(\cdot)=\left(b_{m+1}(\cdot), \ldots, b_{m+n}(\cdot)\right)$ be an element of $\mathcal{B}$. For each $(\mathbf{q}, \mathbf{b}(\mathbf{q})) \in \mathcal{Q} \times \mathcal{B}$, the price vector $\mathbf{p}(\mathbf{q}, \mathbf{b}(\mathbf{q}))=\left(p_{x}(\mathbf{q}, \mathbf{b}(\mathbf{q})), 1\right)$ is such that

$$
p_{x}(\mathbf{q}, \mathbf{b}(\mathbf{q}))=\left\{\begin{array}{cc}
\frac{B(\mathbf{q})}{Q} & \text { if } Q \neq 0 \\
0 & \text { if } Q=0
\end{array},\right.
$$

with $B(\mathbf{q})=\sum_{i=m+1}^{m+n} b_{i}(\mathbf{q})$. For each $(\mathbf{q}, \mathbf{b}(\mathbf{q})) \in \mathcal{Q} \times \mathcal{B}$, the commodity bundle $\left(x_{i}(\mathbf{q}, \mathbf{b}(\mathbf{q})), y_{i}(\mathbf{q}, \mathbf{b}(\mathbf{q}))\right)$ of a seller $i$ is given by

$$
\begin{aligned}
& x_{i}(\mathbf{q}, \mathbf{b}(\mathbf{q}))=x_{i}^{0}-q_{i}, \\
& y_{i}(\mathbf{q}, \mathbf{b}(\mathbf{q}))=p_{x}(\mathbf{q}, \mathbf{b}(\mathbf{q})) \cdot q_{i},
\end{aligned}
$$

for $i=1, \ldots, m$, and the commodity bundle $\left(x_{i}(\mathbf{q}, \mathbf{b}(\mathbf{q})), y_{i}(\mathbf{q}, \mathbf{b}(\mathbf{q}))\right)$ of a buyer $i$ is given by

$$
\begin{aligned}
& x_{i}(\mathbf{q}, \mathbf{b}(\mathbf{q}))=\left\{\begin{array}{cl}
\frac{b_{i}(\mathbf{q})}{p_{x}(\mathbf{q}, \mathbf{b}(\mathbf{q}))} & \text { if } p_{x}(\mathbf{q}, \mathbf{b}(\mathbf{q})) \neq 0 \\
0 & \text { if } p_{x}(\mathbf{q}, \mathbf{b}(\mathbf{q}))=0
\end{array},\right. \\
& y_{i}(\mathbf{q}, \mathbf{b}(\mathbf{q}))=y_{i}^{0}-b_{i}(\mathbf{q}),
\end{aligned}
$$

for $i=m+1, \ldots, m+n$. The payoff function of an agent $i$ is $\pi_{i}(\mathbf{q}, \mathbf{b}(\mathbf{q}))=$

\footnotetext{
15 Dickson and Hartley (2013a) consider a sequential market share game and Busetto et al. (2008) consider a sequential reformulation of the Shapley window model.
} 
$u_{i}\left(x_{i}(\mathbf{q}, \mathbf{b}(\mathbf{q})), y_{i}(\mathbf{q}, \mathbf{b}(\mathbf{q}))\right)$, for $i=1, \ldots, m+n$. The sequential bilateral oligopoly model is then a set $\Gamma^{\prime \prime}=\left\{\left(\mathcal{Q}_{i}, \pi_{i}(\cdot)\right)_{i=1}^{m},\left(\mathcal{B}_{i}, \pi_{i}(\cdot)\right)_{i=m+1}^{m+n}\right\}$.

We now define a subgame-perfect Nash equilibrium (hereafter SPNE) which is the equilibrium concept we use in this dynamic game.

Definition 4 A strategy profile $(\hat{\mathbf{q}}, \hat{\mathbf{b}}(\hat{\mathbf{q}}))$ is a SPNE for $\Gamma^{\prime \prime}$ if and only if it is a Cournot-Nash equilibrium in every subgame of the game $\Gamma^{\prime \prime}$.

Note that in the sequential bilateral oligopoly the subgames are the whole game and the subgames in which buyers choose their optimal bids following any vector of offers from the sellers. We now consider an example to illustrate how to find the SPNE and how to find the limit of a sequence of SPNE when we partially replicate the exchange economy. We stress again that the limit is not a SPNE as the underlying game is not well-defined at the limit.

Example 5 Consider the same partially replicated exchange economy defined in Example 4. As before, to simplify the analysis, we consider a symmetric SPNE that can be computed as follows. We first find a symmetric Nash equilibrium among the buyers for any feasible strategies of the sellers (i.e., in any buyers' subgame). We then substitute the equilibrium strategies of the buyers in the sellers' payoff functions to determine their reaction functions given the responses of the buyers, after which we can find mutually consistent best responses among the sellers. The strategy profile obtained by this method is a SPNE. It is immediate to verify that each buyer's maximisation problem is as in (10). Therefore the best response of the buyer $3 h$ solves the first order condition in (11) which becomes in this case

$$
\frac{q_{1}+q_{2}}{\tilde{B}(\mathbf{q})}\left(1-\frac{\frac{1}{r} b_{3 h}(\mathbf{q})}{\tilde{B}(\mathbf{q})}\right)\left(3-b_{3 h}(\mathbf{q}) \frac{q_{1}+q_{2}}{\tilde{B}(\mathbf{q})}\right)-1=0 .
$$

Since we consider a symmetric SPNE where $\hat{b}_{3 j}(\mathbf{q})=\hat{b}_{4 j}(\mathbf{q})=\hat{b}(\mathbf{q})$ for $j=1, \ldots, r$, from the previous equation we obtain

$$
\hat{b}(\mathbf{q})=\frac{q_{1}+q_{2}}{2} k\left(3-\frac{q_{1}+q_{2}}{2}\right),
$$

with $k=1-\frac{1}{2 r}$. Consider next the maximisation problem of seller 1 . If we substitute the strategy $\hat{b}(\mathbf{q})$ in the seller's payoff function we obtain

$$
\begin{gathered}
\max _{q_{1}} \ln \left(1+\left(3-q_{1}\right)\right)+2 \frac{q_{1}+q_{2}}{2} k\left(3-\frac{q_{1}+q_{2}}{2}\right) \frac{1}{q_{1}+q_{2}} q_{1}, \\
0 \leq q_{1} \leq 3 .
\end{gathered}
$$

The first order condition of the seller's unconstrained maximisation problem is

$$
\frac{\partial \pi_{1}}{\partial q_{1}}=-\frac{1}{4-q_{1}}+\frac{6 k-2 k q_{1}-k q_{2}}{2}=0 .
$$

Since we consider a symmetric SPNE where $\hat{q}_{1}=\hat{q}_{2}=\hat{q}$, the previous equation implies 


$$
\hat{q}=\frac{9 k-\sqrt{9 k^{2}+6 k}}{3 k} .
$$

Therefore, by combining equations (14) and (15), we obtain the following SPNE for the sequential bilateral oligopoly

$$
\begin{array}{r}
\left(\hat{q}_{1}, \hat{q}_{2}, \hat{b}_{31}, \ldots, \hat{b}_{3 r}, \hat{b}_{41}, \ldots, \hat{b}_{4 r}\right)=\left(\frac{9 k-\sqrt{9 k^{2}+6 k}}{3 k}, \frac{9 k-\sqrt{9 k^{2}+6 k}}{3 k},\right. \\
\quad \frac{3 \sqrt{9 k^{2}+6 k}-3 k-2}{3}, \ldots, \frac{3 \sqrt{9 k^{2}+6 k}-3 k-2}{3}, \\
\left.\frac{3 \sqrt{9 k^{2}+6 k}-3 k-2}{3}, \ldots, \frac{3 \sqrt{9 k^{2}+6 k}-3 k-2}{3}\right) .
\end{array}
$$

The limit of the SPNE for $r \rightarrow \infty$ is $\bar{q}_{i}=\frac{9-\sqrt{15}}{3}$ for sellers and $\bar{b}_{i j}(\overline{\mathbf{q}})=\frac{3 \sqrt{15}-5}{3}$ for buyers. At the limit the price vector is $\mathbf{p}(\overline{\mathbf{q}}, \overline{\mathbf{b}}(\overline{\mathbf{q}}))=\left(\frac{\sqrt{15}}{3}, 1\right)$ and the sellers' and buyers' commodity bundles are

$$
\begin{aligned}
& \left(x_{i}(\overline{\mathbf{q}}, \overline{\mathbf{b}}(\overline{\mathbf{q}})), y_{i}(\overline{\mathbf{q}}, \overline{\mathbf{b}}(\overline{\mathbf{q}}))\right)=\left(\frac{\sqrt{15}}{3}, \frac{3 \sqrt{15}-5}{3}\right), \text { for a seller } i, \\
& \left(x_{i j}(\overline{\mathbf{q}}, \overline{\mathbf{b}}(\overline{\mathbf{q}})), y_{i j}(\overline{\mathbf{q}}, \overline{\mathbf{b}}(\overline{\mathbf{q}}))=\left(\frac{9-\sqrt{15}}{3}, \frac{20-3 \sqrt{15}}{3}\right), \text { for a buyer } i j .\right.
\end{aligned}
$$

It is immediate to see that the commodity bundles at the limit of the SPNE are different to those at the limit of the Cournot-Nash equilibrium in which moves are simultaneous, but are the same as those at the Cournot-Walras equilibrium. We stress again that in this framework all agents are treated symmetrically and the different behaviours of sellers and buyers are obtained endogenously at the limit of the SPNE. With this last example, we have shown that sequential bilateral oligopoly in which it is exogenously specified that sellers move first and buyers move second can provide a closed market model to study asymmetric oligopoly in which the buyers are assumed to behave as price takers by partially replicating the underlying exchange economy. Furthermore, this model can provide a foundation for the Cournot-Walras approach. It is worth stressing that the price equation (13) in the many buyer limit corresponds to the inverse demand function in Example 1. In mixed exchange economies, Busetto et al. (2008) showed that the set of the Cournot-Walras equilibrium allocations coincides with a particular subset of SPNE allocations of the two-stage reformulation of the Shapley window model. 


\section{Walras equilibrium and welfare}

The Walrasian analysis in the synthesis reached in the contributions of Debreu (1959), Arrow and Hahn (1971) and McKenzie (2002) crucially relies on the assumption of price-taking, i.e., all agents are assumed to behave competitively. It is then important to study under which conditions on the fundamentals of an economy agents consider prices as given endogenously in equilibrium, without making ad hoc assumptions. This is the problem of providing a strategic foundation for perfect competition, which is similar in spirit to the problem of finding a foundation for models of oligopoly. In fact, a strategic foundation for perfect competition can also be provided by considering continuum exchange economies or replicated exchange economies. ${ }^{16}$ In cooperative game theory Aumann (1964) provided a foundation for perfect competition in economies with a continuum of agents by showing an equivalence result between the core and the Walras allocation. Subsequently, in noncooperative game theory, Dubey and Shapley (1994) and Codognato and Ghosal (2000) considered strategic market games with a continuum of agents and they show equivalence results between the Cournot-Nash and Walras allocations. Those results are based on the fact that when there is a continuum of agents everyone is negligible and cannot influence prices. The second approach based on replicated exchange economies was pioneered in cooperative game theory by Edgeworth (1881) and further analysed by Debreu and Scarf (1963). ${ }^{17}$ Subsequently, Dubey and Shubik (1978), Sahi and Yao (1989), and Amir et al. (1990) applied this technique to strategic market games. They show that when all agents in the economy are replicated the allocation at the limit of the Cournot-Nash equilibrium corresponds to the allocation at the Walras equilibrium. Those results are heuristically based on the fact that when the number of agents increases their influence on prices decreases and in the limit totally disappears. ${ }^{18}$

We now show how the bilateral oligopoly model can be employed to provide a foundation for perfect competition by considering replicated exchange economies. Consider the exchange economy $\mathcal{E}=\left\{\left(u_{i}(\cdot),\left(x_{i}^{0}, y_{i}^{0}\right)\right)_{i=1}^{m+n}\right\}$. A replicated exchange economy consists in an exchange economy where all agents of $\mathcal{E}$ are replicated $r$ times. We now define the Walras equilibrium concept.

Definition 5 A Walras equilibrium is a pair $\left(p^{*},\left(x_{i}^{*}, y_{i}^{*}\right)_{i=1}^{n+m}\right)$ of a price vector and an allocation such that each commodity bundle $\left(x_{i}^{*}, y_{i}^{*}\right)$ maximises agent $i$ 's utility function within their budget set, for $i=1, \ldots, m+n$, and all markets clear, i.e., $\sum_{i=1}^{m+n} x_{i}^{*}=\sum_{i=1}^{m+n} x_{i}^{0}$ and $\sum_{i=1}^{m+n} y_{i}^{*}=\sum_{i=1}^{m+n} y_{i}^{0}$.

From the results in the previous literature, we can conjecture that in replicated exchange economies all agents lose market power and at the limit for $r \rightarrow \infty$ they all

\footnotetext{
${ }^{16}$ These different approaches are illustrated by the distinction between limit theorems and theorems in the limit (see Gale (2000)). See Mas-Colell (1982) for a study on the links between the two approaches.

${ }^{17}$ Note that this replica differs from the partial replica defined in Sect. 4 in two respects: all agents in the economy are replicated and it does not require to associate a weight to each agent.

${ }^{18}$ Mas-Colell (1980) surveyed the main contributions on the foundations of perfect competition by considering other noncooperative approaches that do not rely on strategic market games.
} 
behave competitively. We now consider an example to illustrate this point by showing that the sellers' and buyers' commodity bundles at the limit of the CournotNash equilibrium correspond to the ones at the Walras equilibrium.

Example 6 Consider the replica of the exchange economy defined in Example 2. We then have an exchange economy with $2 r$ sellers and $2 r$ buyers, i.e., $u_{i j}(x, y)=$ $\ln (1+x)+y$ and $\left(x_{i j}^{0}, y_{i j}^{0}\right)=(3,0)$, for $i=1,2$ and $j=1, \ldots, r$ and $u_{i j}(x, y)=$ $3 x-\frac{1}{2} x^{2}+y$ and $\left(x_{i j}^{0}, y_{i j}^{0}\right)=(0,5)$, for $i=3,4$ and $j=1, \ldots, r$. The Walras equilibrium of the replicated exchange economy is ${ }^{19}$

$$
\begin{aligned}
& \left(p_{x}^{*}, p_{y}^{*}\right)=\left(\frac{\sqrt{5}-1}{2}, 1\right), \\
& \left(x_{i j}^{*}, y_{i j}^{*}\right)=\left(\frac{\sqrt{5}-1}{2}, 2 \sqrt{5}-3\right), \text { for } i=1,2 \text { and } j=1, \ldots, r \\
& \left(x_{i j}^{*}, y_{i j}^{*}\right)=\left(\frac{7-\sqrt{5}}{2}, 8-2 \sqrt{5}\right), \text { for } i=3,4 \text { and } j=1, \ldots, r .
\end{aligned}
$$

By following the same steps as in Example 3, we obtain a Cournot-Nash equilibrium

$$
\left(\hat{q}_{11}, \ldots, \hat{q}_{1 r}, \hat{q}_{21}, \ldots, \hat{q}_{2 r}, \hat{b}_{31}, \ldots, \hat{b}_{3 r}, \hat{b}_{41}, \ldots, \hat{b}_{4 r}\right)
$$

such that $\hat{q}_{i j}=\frac{7 k-\sqrt{k^{2}+4}}{2 k}$ for $i=1,2$ and $j=1, \ldots, r$ and $\hat{b}_{i j}=\frac{2 k \sqrt{k^{2}+4}-2 k^{2}-1}{k}$ for $i=$ 3,4 and $j=1, \ldots, r$ with $k=1-\frac{1}{2 r}$. The limit of this Cournot-Nash equilibrium as $r \rightarrow \infty$ is $\bar{q}_{i j}=\frac{7-\sqrt{5}}{2}$ for sellers and $\bar{b}_{i j}=2 \sqrt{5}-3$ for buyers. At the limit the price vector is $\mathbf{p}(\overline{\mathbf{q}}, \overline{\mathbf{b}})=\left(\frac{\sqrt{5}-1}{2}, 1\right)$ and the sellers' and buyers' commodity bundles are

$$
\begin{aligned}
& \left(x_{i j}(\overline{\mathbf{q}}, \overline{\mathbf{b}}), y_{i j}(\overline{\mathbf{q}}, \overline{\mathbf{b}})\right)=\left(\frac{\sqrt{5}-1}{2}, 2 \sqrt{5}-3\right), \text { for a seller } i j, \\
& \left(x_{i j}(\overline{\mathbf{q}}, \overline{\mathbf{b}}), y_{i j}(\overline{\mathbf{q}}, \overline{\mathbf{b}})\right)=\left(\frac{7-\sqrt{5}}{2}, 8-2 \sqrt{5}\right), \text { for a buyer } i j .
\end{aligned}
$$

It is immediate to see that the commodity bundles at the limit of the Cournot-Nash equilibrium correspond to the ones at the Walras equilibrium of the underlying exchange economy. This example further clarifies that the assumption of competitive behaviour is justified when there are many of each type of agent.

It is worth noting that this convergence to the Walras equilibrium in terms of commodity bundles, when all agents are replicated, is also obtained with the Cournot-Walras equilibrium and the SPNE. These results, obtained for particular examples, suggest that the timing of the model is not relevant when considering a foundation for perfect competition. Lahmandi-Ayed (2001) proved the converge of a Cournot-Walras equilibrium to the Walras equilibrium in exchange economies. As

\footnotetext{
${ }^{19}$ It is straightforward to verify that sellers' and buyers' commodity bundles are the same for any $r$.
} 
mentioned above, Dubey and Shubik (1978), Amir et al. (1990), and Sahi and Yao (1989) studied the converge of a Cournot-Nash equilibrium to the Walras equilibrium in strategic market games. Koutsougeras and Meo (2018) considered the convergence of a Cournot-Nash equilibrium to the Walras equilibrium for general sequences of economies whose distribution of characteristics has compact support by using the model developed by Postlewaite and Schmeidler (1978) and Peck et al. (1992).

We conclude this section by making some welfare considerations on the equilibrium concepts used throughout the paper. First of all, by the first welfare theorem, the Walras equilibrium is Pareto efficient. In contrast, all other allocations found in Examples 2-5 are Pareto inefficient: it is possible to find other commodity bundles which Pareto dominate them. In the following table we report the utility levels of sellers and buyers in the different examples.

\begin{tabular}{llllll}
\hline & \multicolumn{2}{l}{ Commodity Bundles } & & \multicolumn{2}{l}{ Utility } \\
\cline { 2 - 3 } & sellers & buyers & & sellers & buyers \\
\hline Cournot-Walras & $\left(\frac{\sqrt{15}}{3}, \frac{3 \sqrt{15}-5}{3}\right)$ & $\left(\frac{9-\sqrt{15}}{3}, \frac{20-3 \sqrt{15}}{3}\right)$ & & 3.035 & 6.460 \\
Cournot-Nash & $\left(\frac{\sqrt{17}-1}{2}, \sqrt{17}-3\right)$ & $\left(\frac{7-\sqrt{17}}{2}, 8-\sqrt{17}\right)$ & & 2.064 & 7.158 \\
Limit of Cournot-Nash & $(1,2)$ & $(2,3)$ & & 2.693 & 7.000 \\
Limit of SPNE & $\left(\frac{\sqrt{15}}{3}, \frac{3 \sqrt{15}-5}{3}\right)$ & $\left(\frac{9-\sqrt{15}}{3}, \frac{20-3 \sqrt{15}}{3}\right)$ & & 3.035 & 6.460 \\
Walras & $\left(\frac{\sqrt{5}-1}{2}, 2 \sqrt{5}-3\right)$ & $\left(\frac{7-\sqrt{5}}{2}, 8-2 \sqrt{5}\right)$ & & 1.953 & 7.837 \\
\hline
\end{tabular}

It is interesting to note that at the Walras equilibrium, the only efficient equilibrium, sellers get the lowest utility while buyers get the highest. Furthermore, sellers get the highest utility at the Cournot-Walras equilibrium (which is the same as the limit of the SPNE in sequential bilateral oligopoly) which means that, in our examples, they are better off when they face competitive buyers in a sequential oligopoly. We finally remark that Examples $2-6$ belong to the general equilibrium framework while Example 1 is a model of partial analysis. For this reason the efficiency of that model cannot be evaluated by using the notion of Pareto efficiency.

\section{Conclusion}

In this paper we have provided a unified framework to compare different equilibrium concepts to study imperfect competition in exchange economies. We have also clarified the differences among symmetric, asymmetric, simultaneous, and sequential oligopoly and analysed the relationships among them in terms of replicated exchange economies and equilibrium concepts. 
By studying our examples we have found some interesting facts. We have seen that bilateral oligopoly can be used to provide a strategic foundation for asymmetric oligopoly models that impose price taking assumptions on some agents, but that this requires a particular timing structure in that those agents that are assumed to be price takers, and are replicated, must move last. Bilateral oligopoly can also be used to provide a strategic foundation for models that assume price taking for all agents, where in contrast timing does not matter. The study of a general strategic foundation for asymmetric oligopoly models will continue to be an interesting area for future research.

It is important to remark that asymmetric oligopoly can be studied by using the partial replica or by considering mixed exchange economies. This alternative approach was introduced by Okuno et al. (1980) and further scrutinised by Busetto et al. $(2008,2011,2017)$ and Busetto et al. (2018, 2020).

Our main focus has been on exchange economies because economies with production raise many theoretical and technical problems (see Hart (1985), GaryBobo (1988), Bonanno (1990) for a survey). To the best of our knowledge, the only contributions on strategic market games with production are Dubey and Shubik (1977) and Chen et al. (2017). A simpler approach was proposed by Gabszewicz and Michel (1997) (see also Dickson and Hartley (2013a)) which considers bilateral oligopoly where only some agents (the sellers) are endowed with a production technology. We leave for further research the study of the different kinds of imperfect competition considered here in economies with production. It is worth highlighting that in a framework with production it is possible to study the differences between sellers maximizing profits and seller maximizing utility functions. This is a classical issue in general equilibrium with imperfect competition. Furthermore, we have restricted our analysis to exchange economies with only two commodities because in a framework with more commodities the results depend on the particular type of strategic market game adopted.

We have discussed related contributions studying the core of exchange economies. This approach, belonging to cooperative game theory, differs from strategic market games which are non-cooperative games. Koutsougeras and Ziros (2008) and Ziros (2011) worked on blending the cooperative approach with strategic market games in atomless continuum economies by considering the core and the Mas-Colell bargaining set respectively. We think that this line of research is very important to shed some light on these two different approaches that can be used to study imperfect competition in bilateral oligopolies but also in more general exchange economies. Indeed, Ziros (2011) remarked that further interesting insights may be obtained with his approach by considering economies with a finite number of agents.

We conclude by mentioning that there is a small literature on experiments in bilateral oligopoly whose contributions are Duffy et al. (2011) and Barreda-Tarrazona et al. (2018). We expect this line of inquiry to become more popular in the coming years. 
Acknowledgements We would like to thank two anonymous referees and the editor for their useful comments and suggestions.

Funding Open Access funding provided by Università degli Studi di Udine.

Open Access This article is licensed under a Creative Commons Attribution 4.0 International License, which permits use, sharing, adaptation, distribution and reproduction in any medium or format, as long as you give appropriate credit to the original author(s) and the source, provide a link to the Creative Commons licence, and indicate if changes were made. The images or other third party material in this article are included in the article's Creative Commons licence, unless indicated otherwise in a credit line to the material. If material is not included in the article's Creative Commons licence and your intended use is not permitted by statutory regulation or exceeds the permitted use, you will need to obtain permission directly from the copyright holder. To view a copy of this licence, visit http://creativecommons.org/ licenses $/ \mathrm{by} / 4.0 \%$.

\section{References}

Amir R, Bloch F (2009) Comparative statics in a simple class of strategic market games. Games Econ Behav 65:7-24

Amir R, Sahi S, Shubik M, Yao S (1990) A strategic market game with complete markets. J Econ Theory $51: 126-143$

Arrow KJ, Hahn FH (1971) General competitive analysis. Holden Day, San Francisco

Aumann RJ (1964) Markets with a continuum of traders. Econometrica 32:39-50

Barreda-Tarrazona I, Garca-Gallego A, Georgantzs N, Ziros N (2018) Market games as social dilemmas. J Econ Behav Organ 155:435-444

Bloch F, Ghosal S (1997) Stable trading structures in bilateral oligopolies. J Econ Theory 74:368-384

Bloch F, Ferrer H (2001a) Trade fragmentation and coordination in strategic market games. J Econ Theory 101:301-316

Bloch F, Ferrer H (2001b) Strategic complements and substitutes in bilateral oligopolies. Econ Lett 70:8387

Bonanno G (1990) General equilibrium theory with imperfect competition. J Econ Surv 4:297-328

Bonisseau J, Florig M (2003) Existence and optimality of oligopoly equilibria in linear exchange economies. Econ Theor 22:727-741

Busetto F, Codognato G, Ghosal S (2008) Cournot-Walras equilibrium as a subgame perfect equilibrium. Int J Game Theory 37:371-386

Busetto F, Codognato G, Ghosal S (2011) Noncooperative oligopoly in markets with a continuum of traders. Games Econ Behav 72:38-45

Busetto F, Codognato G, Ghosal S (2017) Asymptotic equivalence between Cournot-Nash and Walras equilibria in exchange economies with atoms and an atomless part. Int J Game Theory 46:975-990

Busetto F, Codognato G, Ghosal S, Julien L, Tonin S (2018) Noncooperative oligopoly in markets with a continuum of traders and a strongly connected set of commodities. Games Econ Behav 108:478-485

Busetto F, Codognato G, Ghosal S, Julien L, Tonin S (2020) Existence and optimality of Cournot-Nash equilibria in a bilateral oligopoly with atoms and an atomless part. Int J Game Theory 49:933-951

Chen G, Korpeoglu CG, Spear SE (2017) Price stickiness and markup variations in market games. J Math Econ 72:95-103

Codognato G (1995) Cournot-Walras and Cournot equilibria in mixed markets: a comparison. Econ Theor $5: 361-370$

Codognato G, Gabszewicz JJ (1991) Équilibres de Cournot-Walras dans une conomie d'change. Revue Économique 42:1013-1026

Codognato G, Ghosal S (2000) Cournot-Nash equilibria in limit exchange economies with complete markets and consistent prices. J Math Econ 34:39-53

Codognato G, Julien L (2013) Noncooperative oligopoly in markets with a Cobb-Douglas continuum of traders. Recherches Économiques de Louvain/Louvain Econ Rev 79:75-88

Cournot AA (1838) Recherches sur les principes mathmatiques de la thorie des richesses. Hachette, Paris 
Debreu G (1959) Theory of value. Yale University Press, New Haven

Debreu G, Scarf H (1963) A limit theorem on the core of an economy. Int Econ Rev 4:235-246

Dickson A (2006) The strategic Marshallian Cross: Shapley and Shubik meet Marshall and Cournot. Ph.D. Thesis, University of Keele

Dickson A (2013a) The effects of entry in bilateral oligopoly. Games 4:283-303

Dickson A (2013b) On Cobb-Douglas preferences in bilateral oligopoly. Recherches Économiques de Louvain/Louvain Econ Rev 79:89-110

Dickson A, Hartley R (2008) The strategic Marshallian cross. Games Econ Behav 64:514-532

Dickson A, Hartley R (2013a) Bilateral oligopoly and quantity competition. Econ Theor 52:979-1004

Dickson A, Hartley R (2013b) On "nice" and "very nice" autarkic equilibria in strategic market games. Manchester School 81:745-762

Dubey P, Shapley LS (1994) Noncooperative general exchange with a continuum of traders: two models. J Math Econ 23:253-293

Dubey P, Shubik M (1977) A closed economic system with production and exchange modelled a game of strategy. J Math Econ 4:253-287

Dubey P, Shubik M (1978) The noncooperative equilibria of a closed trading economy with market supply and bidding strategies. J Econ Theory 17:1-20

Duffy J, Matros A, Temzelides T (2011) Competitive behavior in market games: evidence and theory. J Econ Theory 146:1437-1463

Edgeworth FY (1881) Mathematical psychics. Augustus M, Kelley

Gabszewicz JJ (2013) Introduction. Recherches Économiques de Louvain/ Louvain Econ Rev 79:5-13

Gabszewicz JJ, Mertens JF (1971) An equivalence theorem for the core of an economy whose atoms are not "too" big. Econometrica 39:713-721

Gabszewicz JJ, Michel P (1997) Oligopoly equilibrium in exchange economies. In: Eaton BC, Harris RG (eds) Trade, technology and economics: essays in honour of Richard G. Lipsey, Edward Elgar, Cheltenham

Gabszewicz JJ, Vial JP (1972) Oligopoly a là Cournot in a general equilibrium analysis. J Econ Theory 4:381-400

Gale D (2000) Strategic foundations of general equilibrium: dynamic matching and bargaining games. Cambridge University Press, Cambridge

Gary-Bobo R (1988) Equilibre général et concurrence imparfaite: un tour d'horizon. Recherches Économiques de Louvain/Louvain Econ Rev 54:53-84

Giraud G (2003) Strategic market games: an introduction. J Math Econ 39:355-375

Groh C (1999) Sequential moves and comparative statics in strategic market games. Department of Economics, University of Mannheim, Mimeo

Hart OD (1985) Imperfect competition in general equilibrium: an overview of recent work. In: Arrow KJ, Honkapohja S (eds) Frontiers of economics. Basil Blackwell, Oxford

Koutsougeras LC, Meo C (2018) An asymptotic analysis of strategic behavior for exchange economies. Econ Theor 66:301-325

Koutsougeras LC, Ziros N (2008) A three way equivalence. J Econ Theory 139:380-391

Lahmandi-Ayed R (2001) Oligopoly equilibria in exchange economies: a limit theorem. Econ Theor 17:665-674

Levando D (2012) A survey of strategic market games. Econ Ann 57:63-106

Mas-Colell A (1980) Noncooperative approaches to the theory of perfect competition: presentation. J Econ Theory 22:121-135

Mas-Colell A (1982) The Cournotian foundations of Walrasian equilibrium theory: an exposition of recent theory. In: Hildenbrand W (ed) Advances in economic theory. Cambridge University Press, Cambridge

McKenzie LW (2002) Classical general equilibrium theory. MIT press, London

Okuno M, Postlewaite A, Roberts J (1980) Oligopoly and competition in large markets. Am Econ Rev 70:22-31

Pantaleoni M (1908) Leone Walras-Autobiografia. Giornale degli Economisti 37:603-610

Peck J, Shell K, Spear S (1992) The market game: existence and structure of equilibrium. J Math Econ 21:271-299

Postlewaite A, Schmeidler D (1978) Approximate efficiency of non-Walrasian Nash equilibrium. Econometrica 46:127-135

Sahi S, Yao S (1989) The noncooperative equilibria of a trading economy with complete markets and consistent prices. J Math Econ 18:325-346 
Shapley LS (1976) Noncooperative general exchange. In: Lin SAY (ed) Theory of measurement of economic externalities. Academic Press, New York

Shapley LS, Shubik M (1977) Trade using one commodity as a means of payment. J Polit Econ 85:937968

Shirai K (2010) An existence theorem for CournotWalras equilibria in a monopolistically competitive economy. J Math Econ 46:1093-1102

Shitovitz B (1973) Oligopoly in markets with a continuum of traders. Econometrica 41:467-501

Shubik M (1973) Commodity, money, oligopoly, credit and bankruptcy in a general equilibrium model. Western Econ J 11:24-38

Ziros N (2011) The bargaining set in strategic market games. J Econ 102:171-179

Publisher's Note Springer Nature remains neutral with regard to jurisdictional claims in published maps and institutional affiliations.

\section{Authors and Affiliations}

\section{Alex Dickson ${ }^{1} \cdot$ Simone Tonin ${ }^{2}$}

$\triangle$ Simone Tonin

simone.tonin@uniud.it

1 Department of Economics, University of Strathclyde, Glasgow G1 1XQ, UK

2 Dipartimento di Scienze Economiche e Statistiche, Università degli Studi di Udine, 33100 Udine, Italy 